\title{
An analysis on the study habits among undergraduate medical students
}

\author{
Rajendran R. ${ }^{1}$, Asokan S. ${ }^{2 *}$, Sneha Thangaraj S. ${ }^{3}$ \\ DOI: https://doi.org/10.17511/ijmrr.2019.i05.09 \\ 1 Ramesh Rajendran, Associate Professor, Department of General Medicine, Velammal Medical College Hospital \& Research Institute, \\ Mumbai, Maharastra, India. \\ 2* Sangeetha Asokan, Assistant Professor, Department of General Medicine, Velammal Medical College Hospital \& Research Institute, \\ Mumbai, Maharastra, India. \\ ${ }^{3}$ Sharon Sneha Thangaraj, 1styear MBBS Student, Velammal Medical College Hospital \& Research Institute, Mumbai, Maharastra, India.
}

Introduction: Study habits is one important factor which influences the academic performance of students. The learning strategies of high achievers are likely to be more effective. The study was aimed to analyse the study habits among undergraduate medical students and compare the study habits of high, average and low achieving undergraduate medical students. Application of effective learning strategies may be helpful in achieving better academic outcomes. Materials and Methods: The study was conducted as a cross sectional, observational study with 118 Final year MBBS students as study participants using Dennis Congos Study Skills Inventory Questionnaire consisting of 51 study habits questions classified according to domains of Text Book reading, Notes taking, Memory, Test Preparation, Concentration, Time management. Results: The percentage of students scoring above the cut off levels in each domain were: Memory: 61/118 (51.69\%), Concentration: 67/118 (56.77\%), Notes taking: 7/118 (5.93\%), Time management: 17/118 (14.40\%), Test preparation: $31 / 118(26.27 \%)$, Text book reading: $35 / 118(29.66 \%)$. The only Study habit that showed significant difference across the high, medium and low achievers was: Ability to pay attention in the class ( $p$ : 0.006). Conclusion:Though the students are talented and fare better in Memory and Concentration skills, there is glaring lack of attitudinal skills like Notes taking, Time management, Test preparation and Textbook reading skills. Paying attention in the class seems to be one most important distinguishing learning strategy determining the academic performance. Teaching- Learning methodologies need to be made more interesting so as to actively engage the attention of low achievers also.

Keywords: Study habits, Dennis Congos Study Skills Inventory, Notes taking, Time management, Test preparation, Textbook reading

\section{Corresponding Author}

Sangeetha Asokan, Assistant Professor, Department of General Medicine, Velammal Medical College Hospital \& Research Institute, Mumbai, Maharastra, India.

Email: asangeetha_6@yahoo.co.in

\section{How to Cite this Article}

Rajendran R, Asokan S, Thangaraj SS. An analysis on the study habits among undergraduate medical students. Int J Med Res Rev. 2019;7(5):404-410. Available From

https://ijmrr.medresearch.in/index.php/ijmrr/article/ view/1086
To Browse

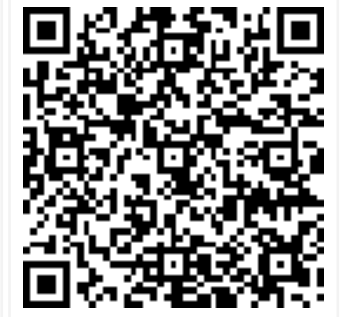

Manuscript Received 2019-09-05

Conflict of Interest No
Review Round 1 2019-09-15

Funding Nil
Review Round 2 2019-09-20

Ethical Approval Yes
Review Round 3

Plagiarism X-checker $6 \%$
Accepted 2019-09-25

Note

(c) 2019 by Ramesh Rajendran, Sangeetha Asokan, Sharon Sneha Thangaraj and Published by Siddharth Health Research and Social Welfare Society. This is an Open Access article licensed under a Creative Commons Attribution 4.0 International License https://creativecommons.org/licenses/by/4.0/ unported [CC BY 4.0]. 


\section{Introduction}

Undergraduate medical education is facing many new challenges in India. Upon graduation, medical students are expected to have developed enough competency in medical knowledge and clinical skills. In spite of the best teachers applied to the medical students, performance of students as well as doctors in the community is perceived to have largely declined [1]. Globally, students with top academic performance and high intellectual capacity usually opt to study medicine. However, once they get enrolled in medical schools, their academic performance varies widely [2]. Study habits is one important factor which influences the academic performance of students [3-8].

Some habits are considered to be more desirable than others from the point of view of academic achievement $[9,10]$. In general, students who achieved success had previously found the best study method for themselves [11]. Aim of education is to help students become effective learners [11]. Process of learning itself must be learned [12]. Learning strategies are behaviors or thoughts that facilitate knowledge, experiences, attitudes, beliefs, and values [13]. Whereas the learning approaches have been given importance in higher education, they have not received enough attention in medical programs [11].

Many students are spending a lot of time using lowefficacy learning techniques [14]. Lack of study skills puts students at a disadvantage and they suffer tremendously at various stages along their student journey [15]. Study skills support is an important factor to consider in helping students achieve success and withstand challenges they face in academic context [16]. Students from all backgrounds need support for smooth progression through the academic semesters [17].

Since academic performance is a highly prized parameter for academic excellence, focused efforts are required in understanding the effective learning strategies that would help in enhancing it. Dissemination of effective learning strategies will in turn benefit average and low performers, while in the long term, this will help in building their selfconfidence [18]. It has been shown that possessing a scheduled plan, profound study along with concentration can improve learning in medical students [19]. Study skills among students can be improved further by better time management and test preparation.
Applying study skills leads to better student learning. Conducting study skill classes for the medical students would help in improving their academic performance. [20]. The study was aimed to analyse the study habits among undergraduate medical students and compare the study habits of high, average and low achieving undergraduate medical students. Application of effective learning strategies may be helpful in achieving better academic outcomes [21]. Objective of the study: To analyse the study habits among undergraduate medical students and compare the study habits of high, average and low achieving undergraduate medical students.

\section{Materials and Methods}

Study Design: Observational study Study setting: Velammal Medical College

Inclusion criteria: Final year Undergraduate medical students of Velammal Medical College Exclusion criteria Students not willing for participation in the study. Students who have submitted invalid responses

Study participants: Final year undergraduate medical students of Velammal Medical College who were willing to participate in the study and who have submitted valid responses.

\section{Study size: 118}

Students Variables: Age group of students: 2122; 44 boys and 74 girls.

Students were categorised based on the average of three General Medicine internal assessments marks held in the final academic year as: High achievers: $\geq 70 \%$; Average: $50-70 \%$; Low achievers: $<50 \%$

Data source: Scores obtained from Dennis Congos Study Skills Inventory Questionnaire

DCSSI (Dennis Congos Study Skills Inventory) questionnaire is well accepted, internationally recognized study habits questionnaire suited for collegiate education used in various studies pertaining to study skills. It consists of 51 questions related to study habits classified according to domains of: Textbook reading, Notes taking, Memory, Test Preparation, Concentration and Time management.

The students were expected to read each of the 51 questions, think carefully about each statement and respond truthfully. Using the scale - Almost always: 
5 , More than half of the time: 4 , About half of the time: 3, Less than half of the time: 2, Almost never: 1 , students were expected to circle the number that best describes their behaviour for that particular study skill. The cut off-scores for the skill domains suggesting change for better grades were: Text Book reading: 30; Notes taking: 20; Memory: 30; Test Preparation: 40; Concentration: 35; Time Management: 20 Institutional ethics committee approval was obtained. Informed consent was obtained from the participants. Questionnaires were distributed after clear explanation of the questions. The responses were collected within a span of 2 weeks. Confidentiality was maintained throughout the study. Results were analysed statistically and $p$ value for statistical significance was analysed for various study habits among high, average and low achievers. Quantitative data was entered into Microsoft Excel and analysed using IBM SPSS 21.0. Key analytic outputs are the total and domain wise score - Overall and across gender and achievement categories. Mean and standard deviation or median and interquartile range were used to summarize the score based on the distribution. The difference in scores across achievement categories was assessed using Kruskal Wallis test. $p$ value of $<0.05$ was considered as indicative of statistical significance.

\section{Results}

Total final year students were 140. Rejected invalid responses were 8 . Responses were considered invalid if some of the questions were not responded or same number was encircled for all the questions. Non-Participants were 14 . Total number of participants were 118 students. Of the 118 students included in the study, high, average and low achievers were $22 / 118$ (18.64\%), 75/118 (63.55\%) and $21 / 118(17.79 \%)$ respectively (Figure 1 ).

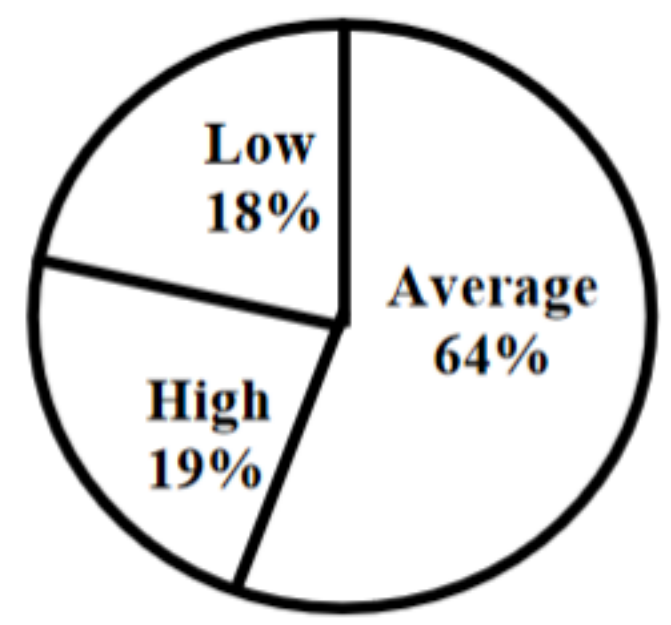

Figure-1: Composition of high, average and low achievers in percentages.

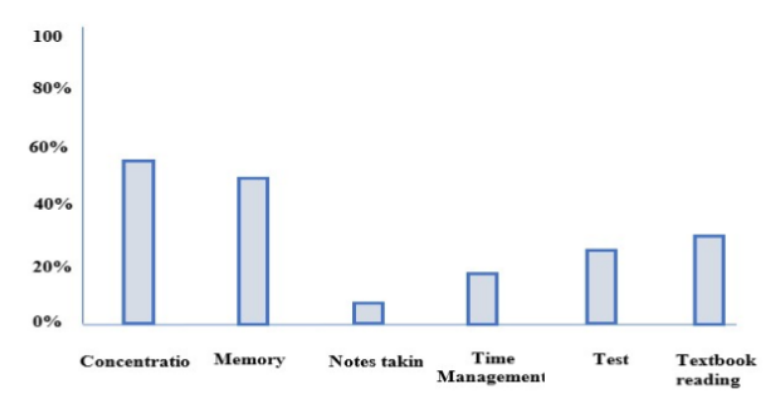

Figure-2: Percentages of Students who scored above the cut-off scores in each domain.

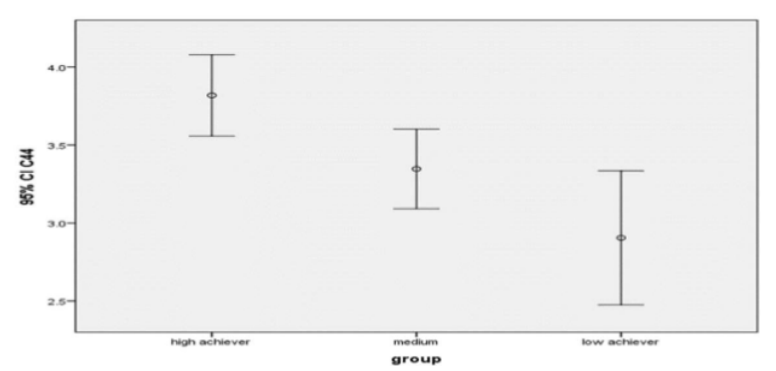

Figure-3: Statistically significant difference p value 0.006 for study skill "able to pay attention in the class" across high, average and low achievers.

The total number and percentage of students scoring above the cut off levels in each domain were:

Memory Domain: 61/118 (51.69\%),

Concentration Domain: $67 / 118(56.77 \%)$,

Notes taking Domain: 7/118 (5.93\%),

Time management Domain: $17 / 118$ (14.40\%),

Test preparation Domain: 31/118 (26.27\%),

Text book reading Domain: 35/118 (29.66\%)

(Figure 2).

The only learning strategy or the study habit that showed significant difference across the high, medium and low achievers was: Ability to pay attention in the class ( $p: 0.006)$. (Figure 3)

Other learning strategies or study habits and domains showed no statistical significant difference across high, average and low achievers. Statistically significant difference ( $p$ value) for various domains across the high, medium and low achievers were Text book reading: 0.33 , Notes taking: 0.31 , Memory: 0.47 , Test preparation 0.41 , Concentration 0.37 , Time management 0.27 (Table 1 ) 
Table-1: Non-statistical difference for study skills domains scores across high, average and low achievers.

\begin{tabular}{|c|c|c|c|c|c|c|c|}
\hline & \multicolumn{6}{|c|}{ Groups } & \multirow[t]{3}{*}{$P$ value } \\
\hline & \multicolumn{2}{|c|}{ High achievers } & \multicolumn{2}{|c|}{ Medium achievers } & \multicolumn{2}{|c|}{ Low achievers } & \\
\hline & Mean score & Standard deviation & Mean score & Standard deviation & Mean score & Standard deviation & \\
\hline Text Book reading & 25.9 & 4.4 & 26.4 & 5.1 & 24.4 & 5.3 & 0.330 \\
\hline Notes Taking & 13.0 & 4.1 & 12.5 & 3.9 & 11.3 & 4.1 & 0.312 \\
\hline Memory & 29.7 & 7.3 & 30.1 & 5.8 & 27.9 & 6.0 & 0.472 \\
\hline Test Preparation & 37.9 & 8.1 & 35.6 & 6.0 & 34.7 & 7.7 & 0.410 \\
\hline Concentration & 36.4 & 4.2 & 35.1 & 5.8 & 34.0 & 5.0 & 0.379 \\
\hline Time management & 14.5 & 5.2 & 12.7 & 4.9 & 13.4 & 4.9 & 0.272 \\
\hline Total & 157.8 & 24.1 & 152.5 & 20.3 & 145.8 & 26.2 & 0.564 \\
\hline
\end{tabular}

\section{Discussion}

Study skills are considered to be important in judging students' overall potential and attainment levels (Nuthana \& Yenagi, 2009). Understandably, to achieve academic excellence, students need to possess essential study skills which include timemanagement, organization, note taking, reading and critical thinking. Some studies have asserted that student success depends on the study skills they adopt to achieve the expected outcomes (Maribeth \& Jill, 2002; Meneghetti, et al., 2007). Psychologists find study skills to be the most contributing factor in students' performance at the university level (Gholiazdeh, 2001) [15].

The teacher of the undergraduate medical student has an important role to play in the development of these skills [22]. Study strategies that are effective in high school may not be as effective in college [23]. At-risk medical students entering medical school plan to increase their number of study hours in the first year of medical school. However, given the busy schedules required of a modern medical student, these expectations may not be congruent with a realistic study schedule. Students must learn to master complex subject material in an efficient and long-lasting manner [24].

Thus, to enhance the quality of education, there is a need to improve the study habits and attitudes of the students. This could be done through provision of developmental programs that will help students build efficient and effective study habits and positive attitudes towards learning, in an early stage of their studies [25].

From the results of the study, the following conclusions can be drawn. Though the students are talented, they need refinement of their study skills.
Majority of the students are unaware of the existence of study skills. Study skills is not given due significance in the undergraduate learning. Of the study skills domains, those that are strikingly deficient among students are Notes taking, Time management, Test preparation and Textbook reading. Memory and Concentration skills also need to be fine-tuned. Improvement of these study skills can lead to increase in grades and overall academic performance of the students.

It was expected before the study that, there would be significant differences in various study habits between the high, average and low achievers. But amazingly, only the study habit - Paying attention in the class was what distinguished the high achievers from others and it was also statistically significant across all the three groups of high, average and low achievers. None other study skills domains or individual study habits were different among high, average and low achievers. This finding should be given due consideration. Key component of Medical learning and skills acquisition in medical field is observation and listening to the teachers which helps in orienting and reforming the student to mature and understand the medical knowledge and wisdom.

This crucial aspect which is often neglected has been well brought out by the study. This information has to be emphasised to the faculties and disseminated to the students as well. Strategies that can improve the attention of the students in the class, particularly the low achievers should be put to effective practice to increase the academic performance of the students. Adoption of newer interactive teaching methods that includes the students' participation in the teaching-learning activities may help in improving the attention of the students in the classes. 
The present study had many similarities to many previously published studies on this topic. In the study by S. Madhavi et al [20], the main problems among students were time management, concentration, note taking and test preparation. The study done by Chitra Nagaraj et al [26], Note taking skills were significantly associated with good performance of medical students. Memorizing notes and failure to organize main ideas and details were associated with bad performance.

The present study results were in accordance with study by Abbasali Nourian et al [27], which observed that marked problems were in the areas of time management, concentration, reading speed, note taking, study habits and comprehension.

In the study by Hafiz Naweed Ahmad et al [28], poor academic performance is associated with poor time management approach to study, excessive use of social networking and poor study habits.

The present study had dissimilarities with the study done by Anuradha Sujai Joshi et al [18] using focused group discussions and in depth interviews, in which significant themes that influenced high academic achievements comprised of hard work in the form of regularity in studies, meticulous preparation of notes, constructive use of time, active utilization of e-learning, regular visit to clinical wards, and incorporating individual learning styles, strategic and deep learning approaches while studying and small group learning.

The present study results were also in contrast with the study of Shanmugananda P et al [29], which concluded that high achievers have a diligent study pattern, they not only study regularly, but were also involved in group discussions and approach their teachers when in doubt.

Limitations of the study were as follows: Students were categorised as high, average and low achievers based on the marks of internal assessment of one subject only. Categorising the students according to internal assessment marks alone can be erroneous. Internal assessment was theoretical only and clinics were not included. Sample size was limited to one batch of students only. It could have been better if other batches were also involved. In spite of clear explanation and instructions, random marking of responses cannot be ruled out. Focused Group Discussions and InDepth Interviews could have been more effective in reflecting the true picture.
Further studies that can recommended based on these results could be on the factors affecting the attention of low achievers in the class using focused group discussions and in-depth interviews and studies on the effect of interactive teaching methods on the improvement of attention of low achievers and academic performance.

Structured Courses on Learning skills can be instituted in the undergraduate program which will be helpful in improving the study skills and thereby improve the academic performance of the students [12]. Carefully planned and implemented study skills courses at the commencement of undergraduate medical training can go a long way in helping to prepare the health professional, not only for the rigors of undergraduate study, but for a lifetime of continuing education and practice [22].

\section{Conclusion}

There is a lot of scope for improvement of the overall Study Skills of undergraduate medical students. Though the students are talented and fare better in Memory and Concentration skills, there is glaring lack of attitudinal skills like Notes taking, Time management, Test preparation and Textbook reading skills. Students need to be sensitised about study skills for better academic outcomes.

Paying attention in the class seems to be one most important distinguishing learning strategy determining the academic performance of students and need to be given high regards in students' education. Therefore, Teaching - Learning Methodologies need to be made more interesting so as to actively engage the attention of low achievers as well.

\section{What the study adds to existing knowledge?}

The observations from this study reveals that the habit of paying attention in the class is often neglected and requires adequate addressal and has not been brought out as a successful learning habit in previous studies.

Certain skills like Time management, Test preparation, Notes taking and Textbook reading which are attitude dependent are more lacking in the current generation learners and is a potential subject for serious study. Analysis of successful learning strategies is complex, and it requires more clarity based on further studies. 


\section{Author's Contributions}

Dr. R. Ramesh: Theme Conception \& Study Design Formulation, Ethical Committee Approval Procurement, Conduct of Study Process, Critical appraisal of Manuscript and Final approval of version to be published. Dr. A. Sangeetha: Manuscript Preparation, Revision of Manuscript, Correspondence process, General supervision and Administrative support. Ms. T. Sharon Sneha: Acquisition, Analysis and Interpretation of Data, Data graphics presentation

\section{Reference}

01. Mandal A, Ghosh A, Sengupta G, Bera T, Das N, Mukherjee $S$. Factors affecting the performance of undergraduate medical students- A perspect ive. Indian J Community Med. 2012;37(2)126-9. doi: 10.4103/0970-0218.96104 [Crossref]

02. Arulampalam W, Naylor R, Smith J. Factors affecting the probability of first year medical student dropout in the UK- a logistic analysis for the intake cohorts of 1980-92. Med Educ. $2004 ; 38(5) 492-503$.

doi: $10.1046 /$ j.1365-2929.2004.01815.x [Crossref]

03. Cepeda NJ, Vul E, Rohrer D, Wixted JT, Pashler $\mathrm{H}$. Spacing effects in learning- a temporal ridgeline of optimal retention. Psychol Sci. 2008;19(11)1095-1102.

doi: $10.1111 /$ j.1467-9280.2008.02209.x [Crossref]

04. Karpicke JD, Roediger HL 3rd. The critical import ance of retrieval for learning. Sci. 2008;319 (5865)966-8.

doi: $10.1126 /$ science.1152 408 [Crossref]

05. Carpenter SK, Wilford MM, Kornell N, Mullaney KM. Appearances can be deceiving- instructor fluency increases perceptions of learning without increasing actual learning. Psychon Bull Rev. 2013;20(6)1350-1356.

doi: 10.3758/s13423-013-0442-z [Crossref]

06. Liew SC, Sidhu J, Barua A. The relationship between learning preferences (styles and approaches) and learning outcomes among preclinical undergraduate medical students. BMC Med Educ. $2015 ; 15 ; 44$.

doi: $\quad 10.1186 / s 12909-015-0327-0$

[Crossref]
07. Lerchenfeldt S, Nyland R. Learning technique utility and preferences among second-year medical students- a pilot study of general and pre-exam study habits. Med Ed Publish. 2016;5. doi: $\quad 10.15694 /$ mep.2016.000096 [Crossref]

08. Ward PJ. First year medical students' approaches to study and their outcomes in a gross anatomy course. Clin Anat. $2011 ; 24(1) 120-127$. doi: $10.1002 /$ ca.21071 [Crossref]

09. Siahi EA, Maiyo JK. Study of the relationship between study habits and academic achievement of students- A case of Spicer Higher Secondary School, India. Int J Edu Admin Pol Stud. 2015;7(7)134-141. doi: $10.5897 /$ IJEAPS2015.0404 [Crossref]

10. Nonis SA, Hudson GI. Performance of College Students- Impact of Study Time and Study Habits. J Edu Business. 2010;85(4)229-238.

doi: $10.1080 / 08832320903449550 \quad$ [Crossref]

11. Cebeci S, Dane S, Kaya M, Yigitoglu R. Medical students' Approaches to Learning and Study Skills. Procedia- Soc Behav Sci. 2013;93;732-6. doi: 10.1016/j.sbspro.2013.09.271 [Crossref]

12. Siddiqui IA, Abdulrahman KAB, Mohammed A. A learning skills course for the 1 st year medical students- an experience at a Saudi medical school. Advan Med Edu Prac. 2015;6; 205-210. doi: 10.2147/AMEP. S77717 [Crossref]

13. Weinstein CE, Ridley DS, Dahl T, Weber ES. Helping students develop strategies for effective learning. Edu Leader. 1989;46(4)17-19. [Crossref]

14. Nyland RL, Sawarynski KE. Setting Students Up for Success- A Short Interactive Workshop Designed to Increase Effective Study Habits. Med Ed Portal. 2017;13;10610.

doi: 10.15766/mep_2374-8265.10610 [Crossref]

15. Naqvi S, Chikwa G, Menon U, Al Kharusi D. Study skills assessment among undergraduate students at a private university college in Oman. Med J Soc Sci. 2018;9(2)139-147.

doi: $10.2478 / \mathrm{mjss}-2018-003$ [Crossref] 
16. Wernersbach BM, Crowley SL, Bates SC, Rosenthal C. Study Skills Course Impact on Academic Self-Efficacy. J Develop Edu. $2014 ; 37(2) 14$.

[Crossref]

17. Blythman, Margo and Orr, Susan (2002) A joined up policy approach to student support. In- Failing Students in Higher Education. Open University Press, Buckingham. Available from: http://ualresearchonline.

arts.ac.uk/id/eprint/7378 [Crossref]

18. Joshi AS, Ganjiwale JD, Varma J, Singh P, Modi JN, Singh T. Qualitative Assessment of Learning Strategies among Medical Students Using Focus Group Discussions and In-depth Interviews. Int J Appl Basic Med Res. 2017;7(1)S33-S37.

doi: 10.4103/ijabmr.IJABMR_144_17 [Crossref]

19. Reid WA, Duvall E, Evans P. Can we influence medical students' approaches to learning?. Med Teach. $2005 ; 27(5) 401-407$.

doi: $10.1080 / 01421590500136410 \quad$ [Crossref]

20. Madhavi S, Naidu AS, Krishnaveni A, Kiran P. Study Skills assessment among Medical Undergraduates-Where they stand. IOSR-JDMS. 2014;13(10)16-19.

[Crossref]

21. Jiraporncharoen $W$, Angkurawaranon C, Chockjamsai $M$, Deesomchok A, Euathrongchit J. Learning styles and academic achievement among undergraduate medical students in Thailand. J Educ Eval Health Prof. 2015;12;38. doi: 10.3352/jeehp.2015.12.38 [Crossref]

22. Raja C Bandaranayake. Oxford Textbook of Medical Education. Oxford University Press. 2013 Oct.

[Crossref]
23. Yip M, Chung O. Relationship of Study Strategies and Academic Performance in Different Learning Phases of Higher Education in Hong Kong. Edu Res Eval. 2005;11(1)61-70.

doi: 10.1080/13803610500110414 [Crossref]

24. Cynthia J Miller. Implementation of a study skills program for entering at-risk medical students. Advan Physiol Edu. 2014;38(3)229-234. doi: $10.1152 /$ advan.00022.2014 [Crossref]

25. Mendezabal MJN. Study Habits and AttitudesThe Road to Academic Success. Open Science Repository Education. Online (Open-access). 2013;e70081928. doi: 10.7392/Education.70081928 [Crossref]

26. Nagaraj C, Pradeep BS. Why do medical students under-perform?- A cross-sectional study from Kempe Gowda Institute of Medical Sciences, Bangalore. J Dr NTR Univers Health Sci. 2014;3(2)92-96.

doi: $10.4103 / 2277-8632.134841$ [Crossref]

27. Nourian A, Mousavinasab SN, Fehri A, Mohammadzadeh A, Mohammadi J. Evaluation of study skills and habits in medical students. South East Asian J Med Educat. 2008;2(1)6164.

[Crossref]

28. Ahmad HN, Asif M. Medical students' learning habits- A mixed method study during clinical rotation in general surgery. J Paki Med Assoc. 2018;68(4)600-606.

[Crossref]

29. Shanmukananda $P, \quad L \quad$ Padma. Identifying learning techniques among high achievers. Int J Basic Clinic Pharmacol. 2013;2(2)203-207. doi:10.5455/2319-2003.ijbcp20130316 [Crossref] 